Article

\title{
Hydrologic Evaluation of TRMM and GPM IMERG Satellite-Based Precipitation in a Humid Basin of China
}

\author{
Zengxin Zhang ${ }^{1,2, *} \mathbb{C}^{\text {, Jiaxi Tian }}{ }^{2}$, Yuhan Huang ${ }^{2}, \mathrm{Xi}_{\mathrm{i}}$ Chen ${ }^{3}{ }^{\circ}$, Sheng $\mathrm{Chen}^{4}$ and \\ Zheng Duan 5 (D) \\ 1 State Key Laboratory of Hydrology-Water Resources and Hydraulics Engineering, Hohai University, \\ Nanjing 210098, China \\ 2 Joint Innovation Center for Modern Forestry Studies, College of Biology and the Environment, \\ Nanjing Forestry University, Nanjing 210037, China; tianjiaxi@njfu.edu.cn (J.T.); ecoyuhan@163.com (Y.H.) \\ 3 Institute of Surface-Earth System Science, Tianjin University, Tianjin 300072, China; xichen@hhu.edu.cn \\ 4 School of Atmospheric Sciences, and Guangdong Province Key Laboratory for Climate Change and Natural \\ Disaster Studies, Sun Yat-sen University, Guangzhou 510275, China; chenshengbj@gmail.com \\ 5 Lancaster Environment Centre, Lancaster University, Lancaster LA1 4YQ, UK; duanzheng2008@gmail.com \\ * Correspondence: zzhang@hhu.edu.cn; Tel.: +86-25-8542-8963
}

Received: 31 December 2018; Accepted: 15 February 2019; Published: 19 February 2019

check for updates

\begin{abstract}
Tropical Rainfall Measurement Mission (TRMM) is one of the most popular global high resolution satellite-based precipitation products with a goal of measuring precipitation over the oceans and tropics. However, in recent years, the TRMM mission has come to an end. Its successor, Global Precipitation Measurement (GPM) mission was launched to measure the earth's precipitation structure, with an aim to improve upon the TRMM project. Both of the precipitation products have their own strengths and weaknesses in resolution, accuracy, and availability. The aim of this study is to evaluate the hydrologic utilization of the TRMM and GPM products in a humid basin of China. The main findings of this study can be summarized as follows: (1) 3B42V7 generally outperforms 3B42V6 in terms of hydrologic performance. Meanwhile, 3B42RTV7 significantly outperforms 3B42RTV6, and showed close performance with the bias-adjusted TRMM Multi-satellite Precipitation Analysis (TMPA) products. (2) The GPM showed better agreement with gauge observation than the TMPA products with lower RB and higher correlation coefficient (CC) values at different time scales. (3) The VIC hydrological model generally outperformed the XAJ hydrological model with lower RB, higher Nash-Sutcliffe Coefficient of Efficiency (NSCE) and CC values; though the 3B42RTV6 and 3B42RTV7 showed higher CC values in simulating the streamflow hydrograph by using the VIC and XAJ hydrological models. It can be found that the conceptual hydrological model was enough for the hydrologic evaluation of TRMM and GPM IMERG satellite-based precipitation in a humid basin of China. This study provides a reference for the comparison of multiple models on watershed scale.
\end{abstract}

Keywords: TRMM; GPM; hydrological model; humid river basin; China

\section{Introduction}

Precipitation is one of the key input data for various hydrological models. The accuracy of precipitation is vital to improve hydrological simulation [1,2]. Ground-based measurement networks (radar or rain gauge) are either sparse in both time and space or do not exist at all due to the climatic conditions, human geography, and other limited conditions [3]. Remote sensing technologies potentially provide a solution to developing spatially distributed estimates of precipitation at the 
watershed scale. Various methods for estimating rain rates from satellite images have been proposed, from several bands of the eletro-magnetic spectrum [4].

More recently, several satellite-based precipitation products have been emerged to provide uninterrupted precipitation time series with quasi-global coverage. These satellite-based precipitation products provide an unprecedented opportunity for hydro-meteorological applications and climate studies [5,6]. Tropical Rainfall Measurement Mission (TRMM) is probably one of the most popular products with the specific goal of measuring precipitation over the oceans and tropics [7]. TRMM was launched in 1997 with its mission scheduled to last just a few years and the TRMM Multi-satellite Precipitation Analysis (TMPA) was upgraded from version 6 (V6) to version 7 (V7) in May 2012. Many studies have reported on the improvement of Version-7 TMPA over earlier Version-6 [8,9]. For example, Chen [6] thought that 3B42V7 clearly improved upon 3B42V6 over China in terms of daily mean precipitation; Yong et al. [10] reported that 3B42RTV7 represented a substantial improvement over 3B42RTV6 with respect to the systematic bias in the low-latitude Mishui basin; Liu [8] found that 3B42V7 detected more rain events than 3B42V6 in June, July, and August along with December, January and February; Jiang et al. [11] revealed that the 3B42RTV7 and 3B42V7 precipitation products had better performance in estimating precipitation in the Ganjiang River basin; Fei et al. [12] indicated that 3B42V7 was better than 3B42V6 at seasonally and monthly scales. Nevertheless, Chen et al. [6] discovered that the $3 \mathrm{~B} 42 \mathrm{~V} 7$ precipitation product showed a slightly downgraded performance at daily scale in the Qinghai-Tibetan plateau.

Now the TRMM mission has come to an end, however, observation of hurricanes and precipitation from space will not end after TRMM. The Global Precipitation Measurement (GPM) mission was launched in February 2014 to improve upon the TRMM project. Since the precipitation measurement by the GPM platform was very similar to its predecessor TRMM, the development of GPM algorithms to improve precipitation retrievals can be addressed through the lessons learnt from the former TRMM mission in terms of precipitation retrievals and its associated uncertainty [13]. Tang et al. [14] evaluated the GPM Day-1 IMERG version 4 (IMERG v4) and TRMM 3B42 v7 products over Mainland China from April to December 2014 at the hourly time scale. Chen [15] compared the GPM version 5 (IMERG v5) and the TMPA ( 3 B42 v7) over a semi-humid to humid climate transition area (Huaihe River basin) from 2015 to 2017 and both satellite precipitation products showed a high pearson correlation coefficient (r, above 0.89) with gauge observations. Omranian and Sharif [16] evaluated the GPM (IMERG) satellite precipitation products over the lower Colorado River basin, Texas, USA and they found all IMERG products performed better when the temporal and spatial resolutions were downscaled. Omranian et al. [17] investigated the Hurricane Harvey and the devastating rainfall to the Houston, Texas, USA during 25-29 August 2017, and the results indicated that the performance of IMERG product was satisfactory in detecting the spatial variability of the storm.

The satellite precipitation products have been widely applied in the hydrologic and related communities [18]. The hydrologic evaluation of TRMM 3B42 products has also been conducted, such as Tobin and Bennett [19] compared the performance of gauge observations and 3B42V6 data by using the SWAT hydrological modeling in South Texas and northern Mexico; Jiang et al. [5] employed the semi-distributed Xin'anjiang model to evaluate three widely used satellite precipitation products (TMPA 3B42V6, TMPA 3B42RT, and CMORPH) in South China and found that these satellite precipitation products have better performance in the streamflow simulation; Xue et al. [20] explored the improvements of the 3B42V7 algorithm relative to its predecessor 3B42V6 using the Coupled Routing and Excess Storage (CREST) hydrologic model in the mountainous Wangchu basin of Bhutan, and found that the 3B42V7 algorithm demonstrates a significant upgrade from 3B42V6 in precipitation accuracy, thus improving its potential hydrological utility. However, the application of satellite data for hydrological applications was still very limited [21], especially, the comparison of different hydrological models was overlooked in evaluating the satellite-based precipitation products.

Although the evaluation of TMPA and GPM satellite precipitation products has been recently investigated in many areas, their hydrological applications in a river basin are still limited. Therefore, 
the objectives are to (1) evaluate the TMPA and GPM precipitation products at a typical humid climate zone which is extremely vulnerable to floods and droughts [22-24]; and (2) compare the TMPA and GPM hydrologic performance of by using VIC and XAJ hydrological model to provide insight into model selection for supporting water resources management in a humid river basin. This work might be beneficial to the improvement of monitoring, modeling, and forecasting techniques in extreme precipitation and streamflow using satellite precipitation products.

\section{Materials and Methods}

\subsection{Study Area}

The Ganjiang River is one of the biggest tributaries of the Poyang Lake River basin. The drainage area is about $83,500 \mathrm{~km}^{2}$, accounting for $51 \%$ of the Poyang Lake River basin. The topography in this basin is complex and the elevation ranges from 2 to $2120 \mathrm{~m}$ above sea level. Low hills lie in the central part of the basin while alluvial plains govern the lower reaches (Figure 1). The Ganjiang River basin is controlled by the subtropical humid monsoon climate and receives approximately 1400-1800 mm of precipitation per year. The heaviest rainfall occurs in the plum rain season between April and June, while monsoon and typhoon rainstorms frequently occur between July and September.

\subsection{Data}

TMPA satellite rainfall products (3B42 3B42RTV6, 3B42 3B42RTV7, 3B42 3B42V6 and 3B42 3B42V7) and GPM precipitation products were used in this study (Table 1). The TMPA datasets used in this study were downloaded from the NASA website (http:/ / trmm.gsfc.nasa.gov/). It has a high temporal $(3 \mathrm{~h})$ and spatial $\left(0.25^{\circ} \times 0.25^{\circ}\right)$ resolution. The 3B42 TMPA dataset is available in two versions: a research-quality product (3B42) released 10-15 days after each month, covering the global latitude belt from $60^{\circ} \mathrm{N}$ to $60^{\circ} \mathrm{S}$ and a near-real-time product (3B42 RT), which is released approximately $9 \mathrm{~h}$ after real-time with the coverage of the latitude belt from $50^{\circ} \mathrm{N}$ to $50^{\circ} \mathrm{S}$. The main difference between the two versions is the use of the rain gauge data for bias correction, which are unavailable in real-time [25]. The 3B42RT uses the TRMM Combined Instrument (TCI) dataset, which includes the TRMM precipitation radar (PR) and TRMM Microwave Imager (TMI), to calibrate precipitation estimates derived from available Low Earth Orbit (LEO) microwave (MW) radiometers. The 3B42 adjusts the monthly accumulations of the 3-h fields from 3B42RT based on a monthly gauge analysis, including the GPCP $1^{\circ} \times 1^{\circ}$ monthly rain gauge analysis and the Climate Assessment and Monitoring System (CAMS) $0.5^{\circ} \times 0.5^{\circ}$ monthly rain gauge analysis [6].

Table 1. Introduction of the five kinds of satellite precipitation products.

\begin{tabular}{ccc}
\hline Products & Period & Spatial Resolution $\left(^{\circ}\right)$ \\
\hline 3B42RTV6 & $2003 / 01-2010 / 12$ & 0.25 \\
3B42V6 & $2003 / 01-2010 / 12$ & 0.25 \\
3B42RTV7 & $2003 / 01-2010 / 12$ & 0.25 \\
3B42V7 & $2003 / 01-2015 / 10$ & 0.25 \\
GPM & $2014 / 05-2015 / 10$ & 0.1 \\
\hline
\end{tabular}

Global Precipitation Measurement (GPM) is a new generation of precipitation products based on TRMM. Compared with the previous satellite precipitation data, GPM has a larger coverage along with higher spatial and temporal resolution [26]. GPM can also capture micro precipitation and solid precipitation more accurately, which is of great significance to the study of precipitation in middle and high latitudes [27]. The GPM-era precipitation product Integrated Multi-satellite Retrievals (IMERG) is the Level 3 multi-satellite precipitation algorithm of GPM. IMERG combines intermittent precipitation estimates from monthly gauge precipitation data, all constellation microwave sensors, and IR-based observations from geosynchronous satellites. IMERG is executed in near real-time and provides two 
precipitation estimate data options: Early and Late [28]. Early option has a 4-h lag and late provides a 12-h lag. The early option precipitation estimate data was used in this research.

Observed precipitation data comes from 35 rain gauge stations in the Ganjiang River basin during 2003-2015. And the stream flow observations at Waizhou hydrological station were used as the outlet of Ganjiang River basin in this study (Figure 1).

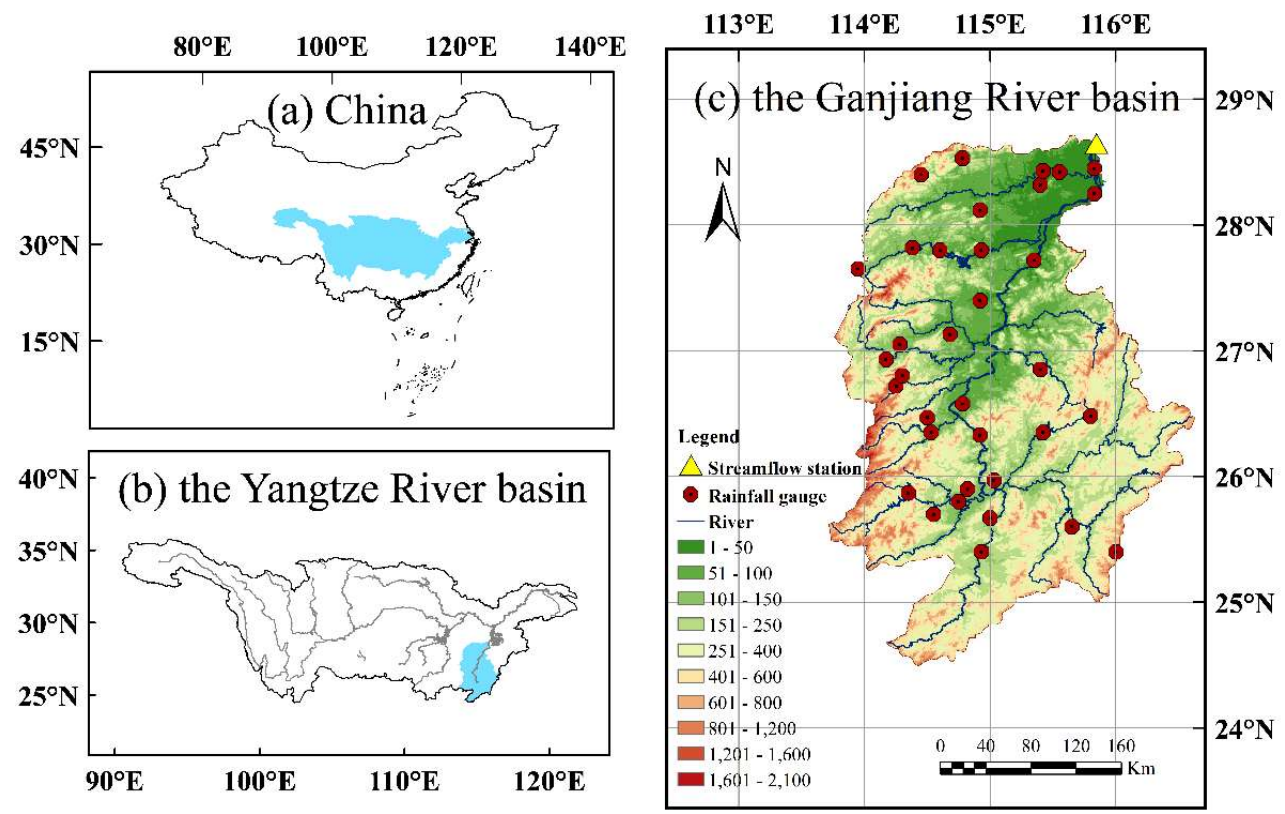

Figure 1. Locations of the study area and the related hydro-meteorological stations.

\subsection{Hydrological Model}

Xin'anjiang Model

The Xin'anjiang model, developed in 1973 and published in 1980, is a semi-distributed conceptual rainfall-runoff model [29]. It uses sub-catchments as primary hydrologic units, allowing the spatial patterns of inputs to be taken into account at the sub-catchment level. The model has been successfully and widely applied in all major river basins in China since its initial development in the 1970s. The XAJ model has a larger number of parameters. There is a clear need to have an effective and efficient method to obtain parameters from measurable quantities of watershed characteristics. The water balance of XAJ is described using the following equation:

$$
S_{t}+W_{t}=S_{0}+W_{0}+\sum_{i=1}^{t}\left(R_{d a y}-Q_{s u r f}-E_{a}-Q_{l a t}-Q_{g w}\right)
$$

where $W_{t}$ is areal mean tension water storage, which includes the storage capacities of three conceptual soil layers (i.e., upper, lower, and deepest layer), and $S_{t}$ is the areal mean free water storage capacity. After calculating the total runoff, three components including surface runoff $Q_{\text {surf }}$, groundwater contribution $Q_{g w}$ and contribution to lateral flow $Q_{l a t}$ are separated. By applying the Muskingum Method to successive sub-reaches, flood routing from sub-basin outlets to the total basin outlet is achieved [29].

\section{VIC Model}

The VIC model was originally developed jointly at the University of Washington and Princeton University. It is a macroscale hydrology model used to simulate various hydrologic variables as well as kinetic energy variables such as soil moisture, snowmelt, direct runoff, baseflow, and various heat 
flux. One of the most distinguishing features of the VIC model is that both water and surface energy budgets are resolved within each grid cell at each time step. In this study, version VIC 4.1.2 was used for the offline simulation [30].

\subsection{Statistical Method}

Relative bias (Bias), correlation coefficient (CC), and root mean square error (RMSE) were used to measure the differences between the four satellite products. The Bias (\%) was used to measure the agreement between the averaged value of gauge data and observed data. The CC was used to assess the linearity of the correlated datasets and the RMSE was used to measure the average error magnitude. For the evaluation of hydrology skills, the indexes Bias, CC, and RMSE were also used to assess the performance of simulated stream flow. Furthermore, the Nash-Sutcliffe Coefficient of Efficiency (NSCE) was used to quantify the performance of the XAJ and VIC hydrological models. The FAR gives the fraction of spurious events among all the events satellites detect [31,32]. The POD indicates the fraction of precipitation events that were correctly detected, whereas the CSI denotes the number of correct forecasts of a rain event, divided by the total of the hits, false alarms and misses [33]. They were defined by the following equations as Table $2[16,20,26]$ :

Table 2. Statistical Performance Measures Used for Evaluation of Satellite Products.

\begin{tabular}{|c|c|}
\hline Indices & Formula \\
\hline \multicolumn{2}{|l|}{ Category 1} \\
\hline Relative bias & $\sum_{\mathrm{n}=1}^{\mathrm{N}}\left(\mathrm{Sat}_{\mathrm{n}}-\mathrm{Gag}_{\mathrm{n}}\right)$ \\
\hline (Bias) & $\sum_{\mathrm{n}=1}^{\mathrm{N}} \mathrm{Gag}_{\mathrm{n}}$ \\
\hline Correlation coefficient & $\frac{1}{N} \sum_{n=1}^{\mathrm{N}}\left(\mathrm{Sat}_{\mathrm{n}}-\overline{\mathrm{Sat}}\right)\left(\mathrm{Gag}_{\mathrm{n}}-\overline{\mathrm{Gag}}\right)$ \\
\hline$(\mathrm{CC})$ & $\left(\mathrm{SD}_{\text {Sat }}\right)\left(\mathrm{SD}_{\text {Gag }}\right)$ \\
\hline $\begin{array}{l}\text { Root mean square error } \\
\text { (RMSE) }\end{array}$ & $\sqrt{\frac{1}{N} \sum_{n=1}^{N}\left(\operatorname{Sat}_{n}-\mathrm{Gag}_{\mathrm{n}}\right)^{2}}$ \\
\hline $\begin{array}{l}\text { Nash-Sutcliffe Coefficient of Efficiency } \\
\text { (NSCE) }\end{array}$ & $1-\frac{\sum_{\mathrm{n}=1}^{\mathrm{N}}\left(\mathrm{Sat}_{\mathrm{n}}-\mathrm{Gag}_{\mathrm{n}}\right)^{2}}{\sum_{\mathrm{n}=1}^{\mathrm{N}}\left(\mathrm{Sat}_{\mathrm{n}}-\overline{\mathrm{Sat}}\right)^{2}}$ \\
\hline \multicolumn{2}{|l|}{ Category 2} \\
\hline $\begin{array}{l}\text { Probability of detection } \\
\text { (POD) }\end{array}$ & $\frac{\mathrm{C}_{\mathrm{sg}}}{\mathrm{C}_{\mathrm{sg}}+\mathrm{C}_{\mathrm{g}} \mathrm{Ms}_{\mathrm{s}}}$ \\
\hline $\begin{array}{l}\text { False alarm ratio } \\
\text { (FAR) }\end{array}$ & $\frac{\mathrm{C}_{\mathrm{s}} \mathrm{M}_{\mathrm{g}}}{\mathrm{C}_{\mathrm{sg}}+\mathrm{C}_{\mathrm{s}} \mathrm{M}_{\mathrm{g}}}$ \\
\hline $\begin{array}{l}\text { Critical success index } \\
\text { (CSI) }\end{array}$ & $\frac{\mathrm{C}_{\mathrm{sg}}}{\mathrm{C}_{\mathrm{sg}}+\mathrm{C}_{\mathrm{s}} \mathrm{M}_{\mathrm{g}}+\mathrm{C}_{\mathrm{g}} \mathrm{M}_{\mathrm{S}}}$ \\
\hline
\end{tabular}

Notes: $n$, number of samples; Sat $_{n}$, satellite rainfall estimate; $\mathrm{Gag}_{n}$, gauge-observed rainfall; Sat, averaged satellite rainfall; Gag, averaged gauge rainfall; $\mathrm{SD}_{\mathrm{Sat}}$, standard deviations of satellite rainfall; $\mathrm{SD}_{\mathrm{Gag}}$, standard deviations of gauge rainfall; $\mathrm{C}_{\mathrm{sg}}$, events captured by satellite and gauge; $\mathrm{C}_{\mathrm{s}} \mathrm{M}_{\mathrm{g}}$, events captured by satellite and missed by gauge; $\mathrm{C}_{\mathrm{g}} \mathrm{M}_{\mathrm{s}}$, events captured by gauge and missed by satellite [16].

The Kolmogorov-Smirnov test (K-S test) was used in this paper. In statistics, the K-S test is a method of calibration, which compares a frequency distribution with a theoretical distribution or two observational distributions. Its original hypothesis $\mathrm{H}_{0}$ : the distributions of two data sets are the same or in accord with the theoretical distribution. If the actual observed value $\mathrm{D}>\mathrm{D}_{\mathrm{n}}, \mathrm{H}_{0}$ is rejected, the $\mathrm{H}_{0}$ hypothesis is accepted [34,35]

The Kriging interpolation method was used to resample the observed precipitation and GPM products as the TMPA spatial resolution $\left(0.25^{\circ}\right)$ to make them comparable.

\section{Results}

\subsection{Evaluation of TRMM Precipitation Products}

The spatial distribution of annual mean precipitation over the Ganjiang River basin derived from the observation and four TMPA products were analyzed during the period of 2003 to 2010 
(Figure 2). It can be seen that the observed annual mean precipitation decreased from the south and west (>1951 mm) to the east and central of the Ganjiang River basin (<1250 mm) (Figure 2a). However, the annual mean precipitation has been significantly undervalued for the 3B42RTV6 product, and it was clear that 3B42RTV7 was significantly improved upon than 3B42RTV6 for the whole basin (Figure 2d,e). As for 3B42V6 and 3B42V7, both of them showed great improvement over real-time products for the precipitation estimation. It was clear that the 3B42V6 and 3B42V7 had good performance in the southern and western edge areas of the basin (Figure 2b,c). Therefore, the bias-adjusted TMPA products 3B42V6 and 3B42V7 showed better agreement with gauge observation than the unadjusted counterparts 3B42RTV6 and 3B42RTV7, especially in capturing the spatial pattern of multi-year precipitation, and temporal pattern of timing, probability distribution of occurrence, and volume. The 3B42V6 and 3B42V7 agreed well with gauge observation with lower RB and high CC at monthly scale. It can be seen that lower annual mean precipitation appeared in the middle reaches of the Ganjiang River basin based on the observed precipitation. However, this "basin" pattern phenomenon did not appear in the TMPA products. This may be a consequence of 3B42V6, 3B42V7 and 3B42RTV7 overestimating the precipitation in the middle reaches of the Ganjiang River basin (Figure 2b,c,e).
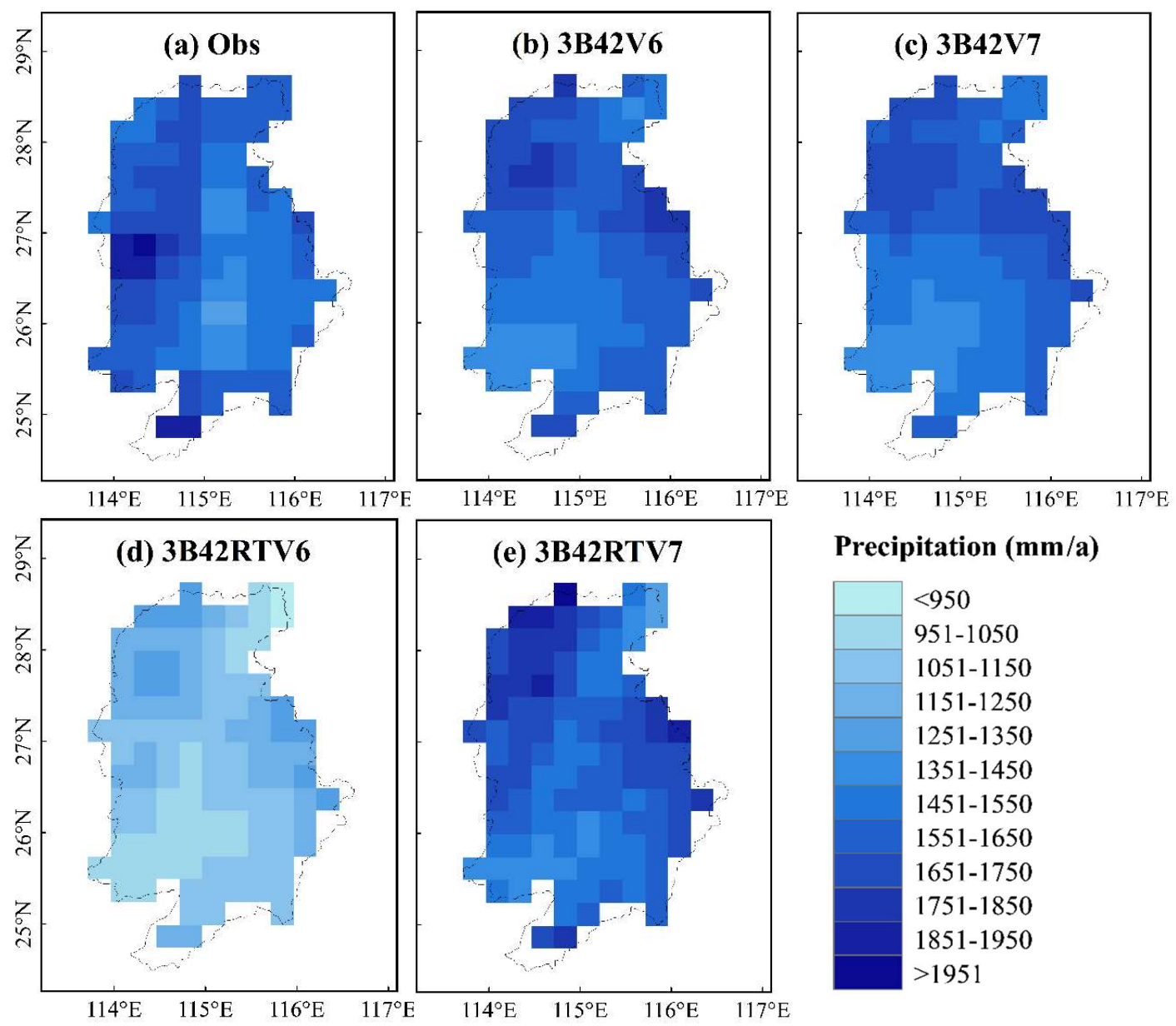

\section{Precipitation $(\mathbf{m m} / \mathbf{a})$}

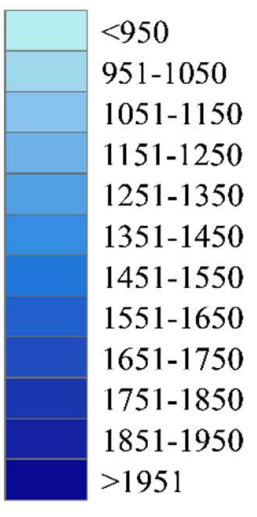

Figure 2. Spatial distribution of annual mean precipitation in the Ganjiang River Basin for TMPA and observed data from 2003 to 2010 (a) Observed data; (b) 3B42V6; (c) 3B42V7; (d) 3B42RTV6; (e) 3B42RTV7).

The comparison between the GPM and 3B42V7 over the Ganjiang River basin from 2014 to 2015 was shown in Figure 3. Similar results can be found that the observed annual mean precipitation decreased from the north to the east and lower precipitation areas mainly distributed in the central and southwestern basin. The 3B42V7 overestimated annual mean precipitation in the north and east 
of Ganjiang River basin while GPM overestimated the precipitation in the east and central regions of the Ganjiang River basin. The 3B42V7 and GPM products generally captured the spatial pattern of precipitation over the Ganjiang River basin, and the GPM agreed better with gauge observation than that of the 3B42V7 at daily scale.
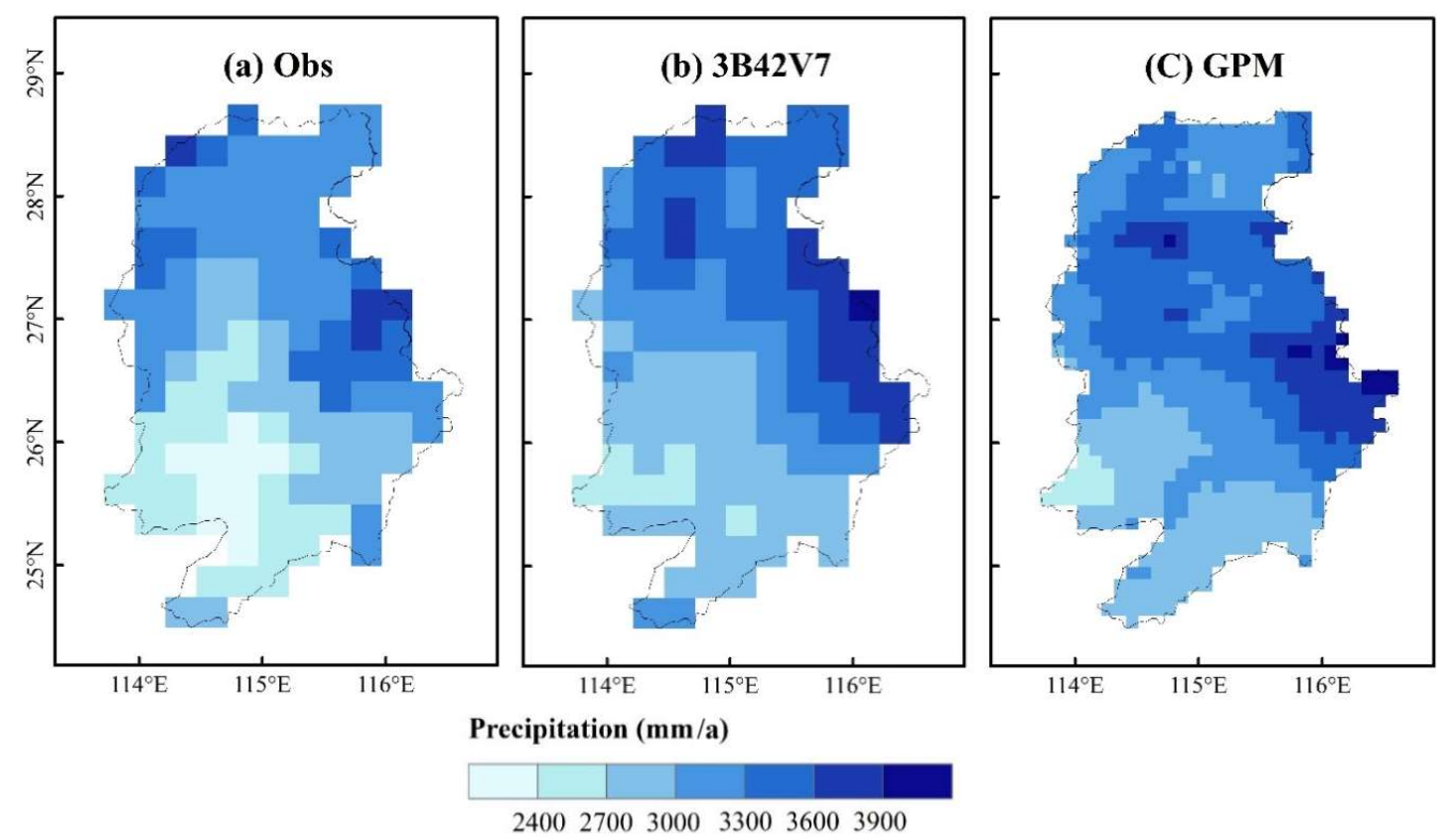

Figure 3. Spatial distribution of annual mean precipitation in the Ganjiang River Basin from GPM, 3B42V7 and Observed data from 2014 to 2015 (a) Observed data; (b) 3B42V7; (c) GPM).

The annual mean TMPA and observed precipitation at different time scales in the Ganjiang River basin from 2003 to 2010 were shown in Figure 4. It can be seen that all of the four TRMM products showed good performance at daily, monthly and annual time scales. However, the 3B42RTV6 product underestimated the monthly precipitation obviously and the product of 3B42RTV7 overestimated the monthly precipitation slightly. As for the annual time scale, it has been greatly underestimated by the 3B42RTV6 precipitation product (Figure 4c). This phenomenon was similar to that of the daily time scale. In addition, it can be found that the TMPA precipitation got its maximum value between May and July, and reached its minimum value around December during the period of 2003 to 2010.

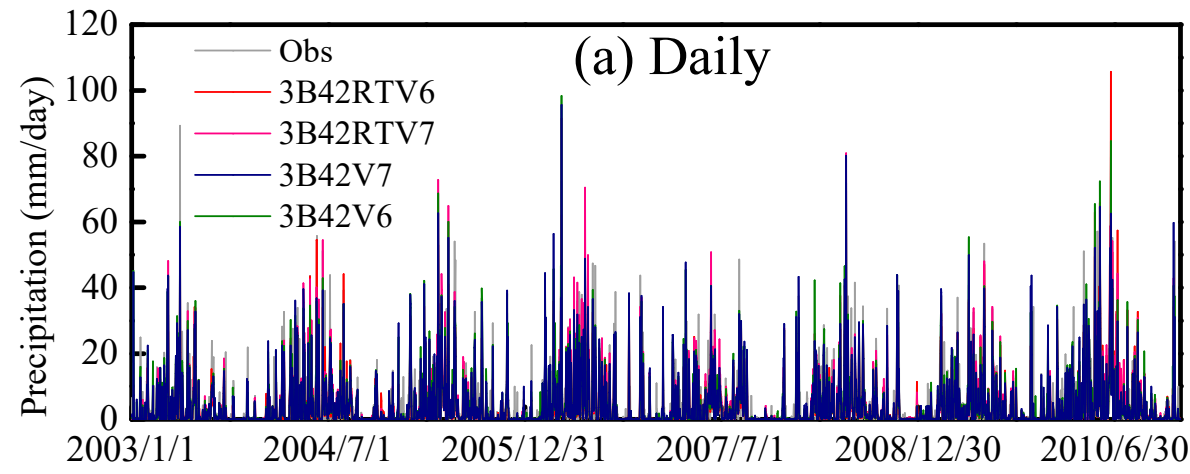

Figure 4. Cont. 

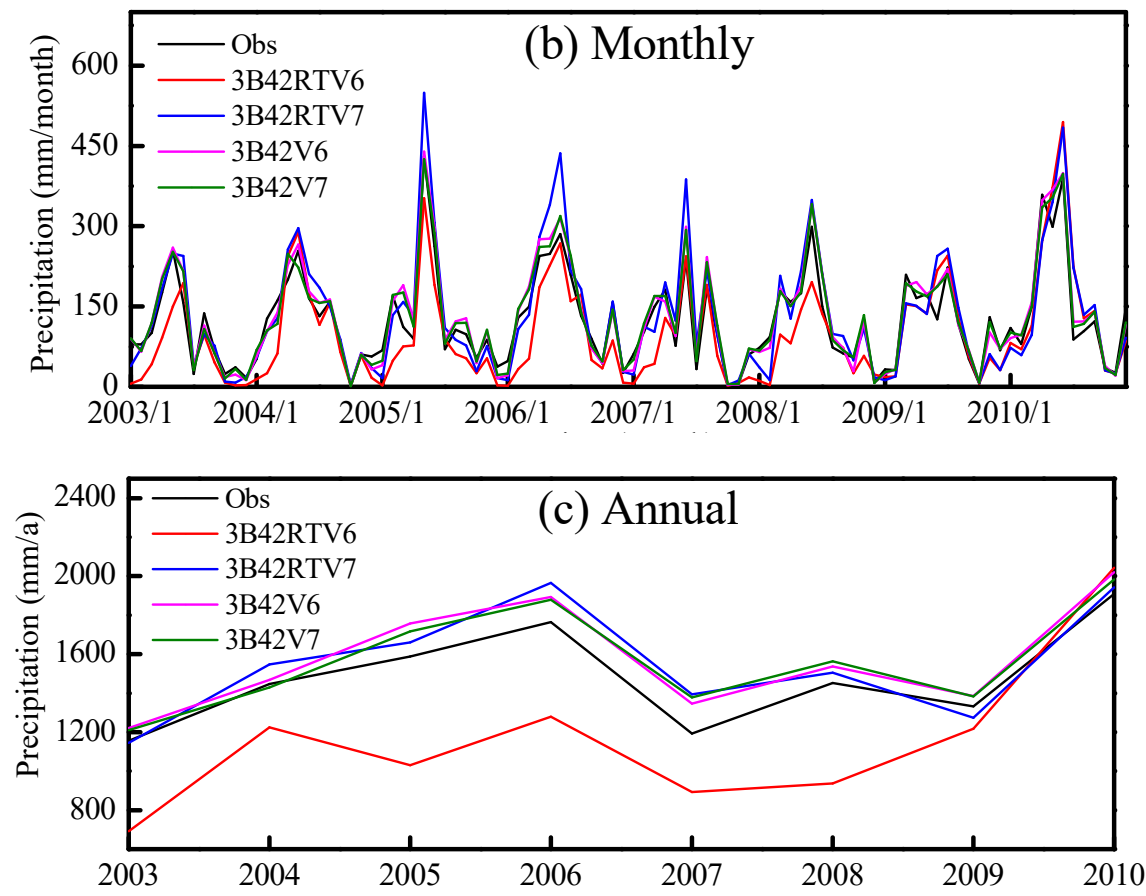

Figure 4. The precipitation time series for TMPA and observed precipitation in the Ganjiang River basin from 2003 to 2010 ((a), Daily; (b), Monthly; (c), Annual).

The correlations between the TMPA and observed precipitation has been analyzed in Table 3 . It can be seen that all of the TMPA products slightly overestimated the precipitation, except for the 3B42RTV6, which strikingly underestimates the precipitation by $24.15 \%$ at the daily time scale. The RMSE and CC value were $5.98 \mathrm{~mm}$ and 0.72 for the 3B42RTV6 product, respectively. In addition, the RB, RMSE and CC values were $3.60 \%, 5.56 \mathrm{~mm}$, and 0.80 for the $3 \mathrm{~B} 42 \mathrm{~V} 6$ product in the Ganjiang River basin, respectively. The 3B42RTV7 showed better performance with high CC (0.79), low RMSE $(5.69 \mathrm{~mm})$, and low RB value $(2.97 \%)$. And the 3B42V7 had much better performance with higher CC (0.82), lower RMSE with the value of $5.24 \mathrm{~mm}$, and lower RB (2.95\%). Generally, the 3 B42V7 product performed much better than other TMPA products in terms of RB, RMSE, and CC. When it came to the monthly scale, the 3B42RTV6 underestimated the precipitation by $26.25 \%$ as a whole. However, the 3B42RTV7 showed much bettr than that of 3B42RTV6 with slight underestimation by $0.30 \%$ as a whole. The 3B42RTV6 and 3B42RTV7 showed good correlations with the gauged precipitation, but the 3B42RTV7 had better performance with higher CC ( 0.90 vs. 0.86$)$ and better RMSE $(1.63 \mathrm{~mm}$ vs. $1.96 \mathrm{~mm}$ ). From the monthly statistics of satellite rainfall products (Table 3), the 3B42V6 was observed to achieve all the best indexes of RB $(0.01 \%)$ and CC (0.95) except RMSE $(1.04 \mathrm{~mm})$, and the 3B42V7 was found to attain all the best indexes of RMSE $(1.00 \mathrm{~mm})$ and CC (0.95) except RB (1.06\%). Overall, 3B42V6 and 3B42V7 perform better than 3B42RTV6 and 3B42RTV7.

Table 3. The difference between the estimated precipitation of four satellite products and the observed precipitation in the Ganjiang River basin.

\begin{tabular}{ccccccc}
\hline $\begin{array}{c}\text { Precipitation } \\
\text { Product }\end{array}$ & \multicolumn{3}{c}{ Daily } & \multicolumn{3}{c}{ Monthly } \\
\cline { 2 - 7 } & RB (\%) & RMSE (mm) & CC & RB (\%) & RMSE (mm) & CC \\
\hline 3B42RTV6 & -24.15 & 5.98 & 0.72 & -26.25 & 1.96 & 0.86 \\
3B42RTV7 & 2.97 & 5.69 & 0.79 & -0.30 & 1.63 & 0.90 \\
3B42V6 & 3.60 & 5.56 & 0.80 & -0.01 & 1.04 & 0.95 \\
3B42V7 & 2.95 & 5.24 & 0.82 & -1.06 & 1.00 & 0.95 \\
\hline
\end{tabular}


Figure 5 showed the daily and monthly precipitation time series for the GPM, 3B32V7, and observed precipitation in the Ganjiang River basin from May 2014 to October 2015. It can be found that there was a good relationship between the GPM and observed precipitation products at daily and monthly scales. Similar results can also be found between the 3B42V7 and observed precipitation. Both of the 3B42V7 and GPM precipitation products were close to that of gauge observations with high CC value at daily and monthly time scale. In addition, there was only small magnitude of overestimation $1.90 \%$ and when it came to the monthly scale 1.34\% for 3B42V7 and GPM, respectively. Although the RB value of GPM was better than 3B42V7, the RMSE of GPM was higher than that of 3B42V7 (17.08 $\mathrm{mm}$ vs. $16.29 \mathrm{~mm})$.
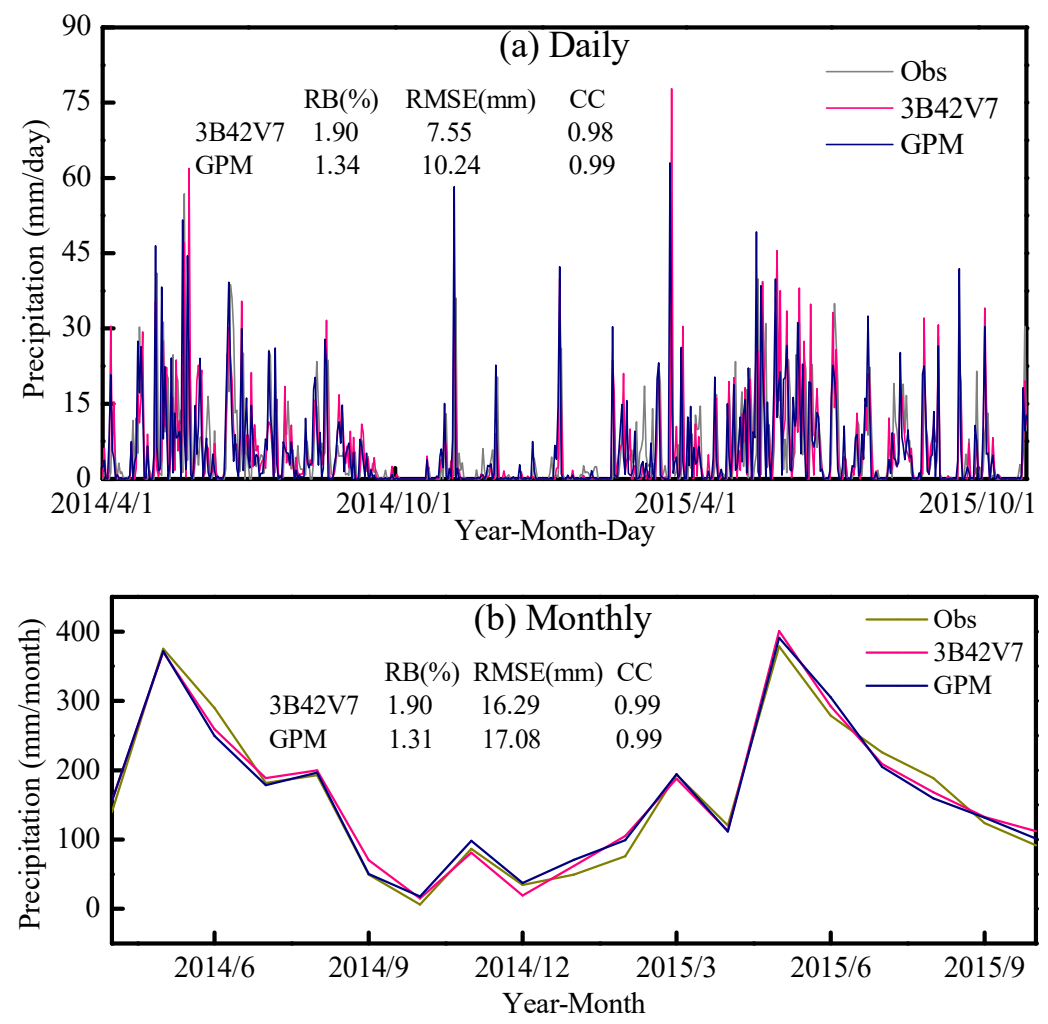

Figure 5. The precipitation time series from GPM and rain gauges in the Ganjiang River basin from May 2014 to October 2015 ((a), Daily; (b), Monthly).

The statistical indices (POD, CSI, and FAR) at the daily time scale for different rainfall thresholds are shown in Figure 6. High values of POD and CSI at rainfall rates from $0.5-10.0 \mathrm{~mm} /$ day indicated that TMPA precipitation products had better performance (Figure $6 a, b$ ). The POD and CSI value decreased with the rainfall rate increasing, and the FAR increased at the same time which revealed the limitation of TMPA products for detecting heavy rainfall events (Figure 6a-c). Therefore, it can be found that all the TRMM products except 3B42RTV6 showed good performance in detecting precipitation in the Ganjiang River basin, especially for rainfall rates of 0.5-10.0 mm/day. Higher POD and CSI values at $0.5-5.0 \mathrm{~mm}$ /day rainfall rates can be found in Figure 6 . This phenomenon revealed that both GPM and 3B42V7 precipitation products performed much better at these rainfall rates. However, the 3B42V7 product showed better performance than the GPM product in detecting precipitation in the Ganjiang River basin, especially at rainfall rates from 0.5-6.0 mm/day. Above all, the 3B42V7 showed the best performance for the detecting precipitation events in the Ganjiang River basin. 

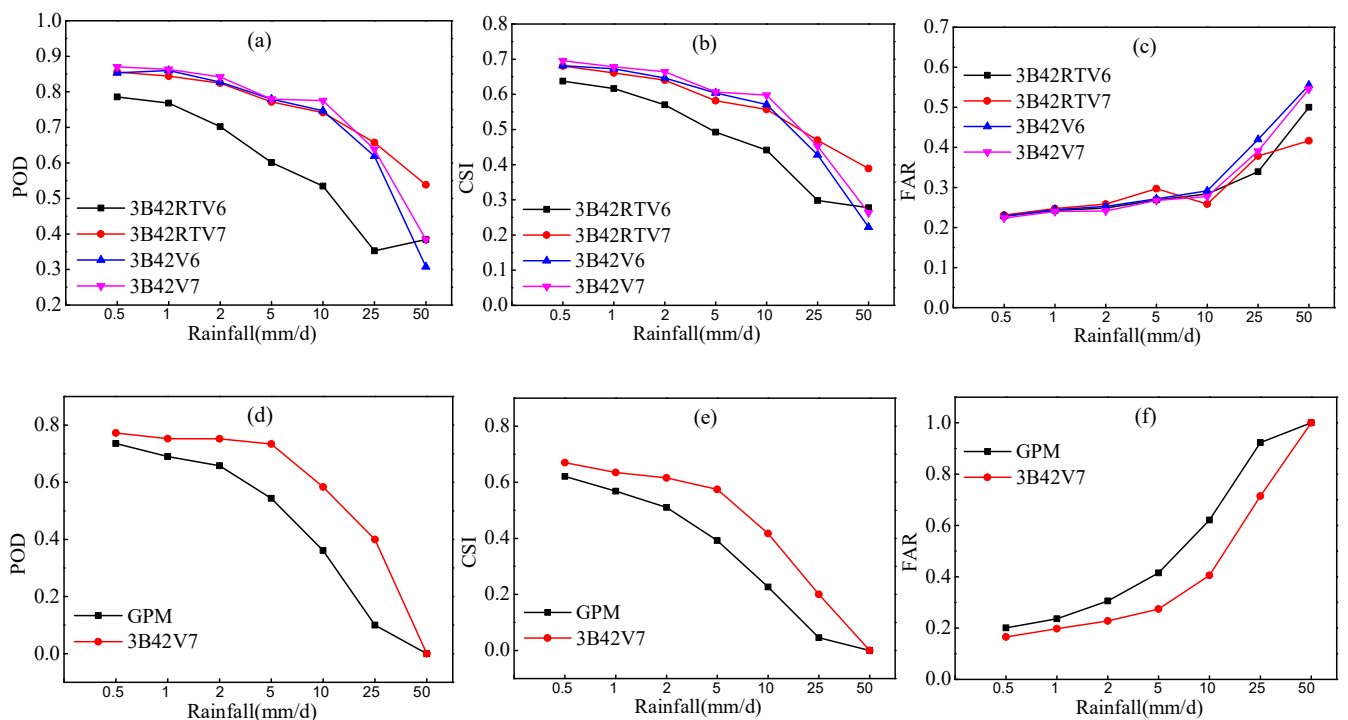

Figure 6. Statistical indices for different rainfall thresholds at daily time scale $((\mathbf{a}, \mathbf{d})$ POD; $(\mathbf{b}, \mathbf{e})$ CSI and $(\mathbf{c}, \mathbf{f})$ FAR).

\subsection{Hydrologic Model Calibration}

The MOCOM-UA algorithm was used in this paper to calibrate the XAJ and VIC hydrologic models' parameter automatically. The method is an effective and efficient methodology for solving the multiple-objective global optimization problem which is an extension of the successful SCE-UA single-objective global optimization algorithm [36]. The XAJ and VIC model Calibrated paraments and calibrated values in Ganjiang River Basin were shown in Tables 4 and 5, respectively.

Table 4. The XAJ model Calibrated Paraments and Calibrated Values in Ganjiang River Basin.

\begin{tabular}{|c|c|c|c|}
\hline Module & Parameter & Description & Value \\
\hline \multirow{4}{*}{ Evapotranspiration } & $\mathrm{Kc}_{\mathrm{C}}$ & Ratio of potential evapotranspiration to pan evaporation & 0.599 \\
\hline & $\mathrm{W}_{\mathrm{um}}$ & Tension water capacity of upper layer $(\mathrm{mm})$ & 20 \\
\hline & $\mathrm{W}_{\mathrm{lm}}$ & Tension water capacity of lower layer (mm) & 60 \\
\hline & $\mathrm{C}$ & Evapotranspiration coefficient of deeper layer & 0.143 \\
\hline \multirow{3}{*}{ Runoff generation } & $\mathrm{W}_{\mathrm{m}}$ & Tension water capacity $(\mathrm{mm})$ & 131.6 \\
\hline & $\mathrm{B}$ & Exponent of distribution of tension water capacity & 0.899 \\
\hline & $\mathrm{I}_{\mathrm{m}}$ & Ratio of impervious area to the total area of the basin & 0.01 \\
\hline \multirow{4}{*}{ Runoff separation } & $S_{m}^{*}$ & Free water capacity $(\mathrm{mm})$ & 64.654 \\
\hline & $E_{x}$ & Exponent of distribution of free water capacity & 0.580 \\
\hline & $\mathrm{K}_{\mathrm{g}}^{*}$ & Outflow coefficient of free water storage to groundwater & 0.223 \\
\hline & $\mathrm{K}_{\mathrm{i}}^{\mathrm{a}}$ & Outflow coefficient of free water storage to interflow & 0.215 \\
\hline \multirow{6}{*}{ Routing } & $\mathrm{C}_{\mathrm{g}}{ }^{*}$ & Recession constant of groundwater storage & 0.839 \\
\hline & $\mathrm{C}_{\mathrm{i}}^{*}$ & Recession constant of interflow storage & 0.988 \\
\hline & $\mathrm{C}_{\mathrm{s}}^{*} \mathrm{~b}$ & Recession constant in the lag-and-route method & 0.85 \\
\hline & $\mathrm{L}_{\mathrm{ag}}{ }^{*}, \mathrm{~b}$ & Lag time $(\mathrm{h})$ & 2 \\
\hline & $\mathrm{K}_{\mathrm{e}}^{\mathrm{c}}$ & Muskingum time constant for each sub-reach (h) & 1 \\
\hline & $X_{e}^{*}$ & Muskingum weighting factor for each sub-reach & 0.31 \\
\hline
\end{tabular}


Table 5. The VIC model Calibrated Parameters and Calibrated Values in Ganjiang River Basin.

\begin{tabular}{cccc}
\hline Parameters & Definition & Value Range & Calibrated Value \\
\hline B & Variable infiltration curve parameter (binfilt) & $0.001-1.0$ & 0.236 \\
\hline Ws & Fraction of maximum soil moisture where non-linear & $\geq 0.5$ & 0.533 \\
baseflow occurs & Fraction of Dsmax where non-linear baseflow begins & $0.001-1.0$ & 0.481 \\
\hline Ds & Maximum velocity of baseflow (mm/day) & $0-50$ & 13.748 \\
\hline d0 & Thickness of each soil moisture layer (m) & $0.1-3.0$ & 0.300 \\
\cline { 1 - 1 } d1 & & & 2.430 \\
\hline d2 & & & 0.533 \\
\hline
\end{tabular}

Table 5 showed the calibrated parameters and calibrated values in Ganjiang River basin. The B, Ws, Ds, Dsmax, d0, d1 and d2 were 0.236, 0.533, 0.481, 13.748, 0.300, 2.430 and 0.533, respectively.

Figure 7 compared the simulated streamflow forced by rain gauge data with the observed streamflow in terms of time series plots at daily scales. The calibration period was selected from 2003 to 2004 and the simulation period was selected from 2005 to 2010 . The results showed that both models were good at simulating the daily hydrograph in this basin and the VIC model has a better effect than the XAJ hydrological model. It can be found that a general agreement existed between the observed and simulated streamflow. However, the simulated streamflow consistently underestimates the peaks, especially in the simulation period and in relatively low flow seasons as well (Figure 7a,b).
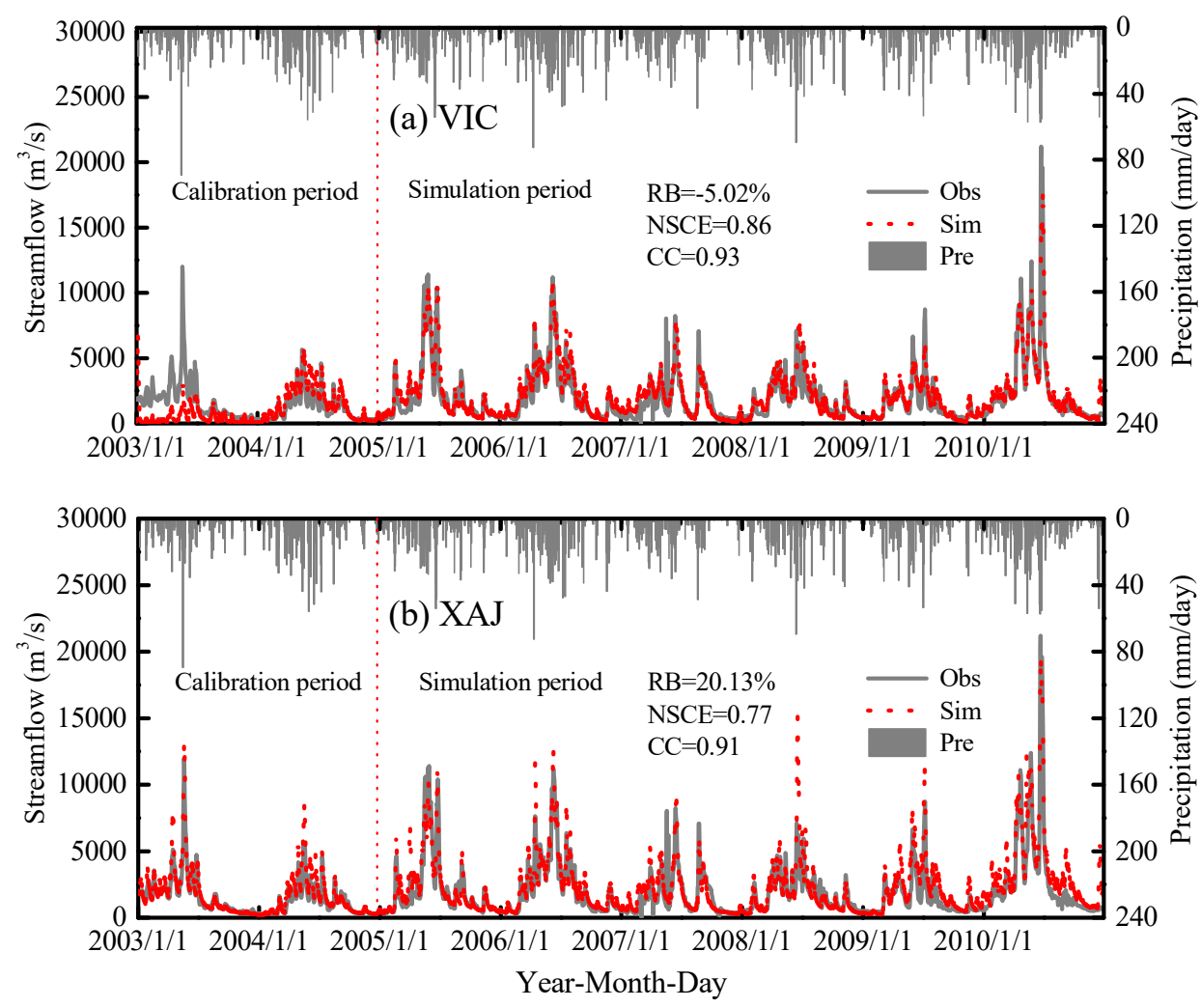

Figure 7. Comparison of observed and simulated streamflow using gauge data as input and corresponding daily precipitation for the calibration period and simulation period ((a) VIX; (b) XAJ).

\subsection{Hydrologic Model Simulation}

The estimated streamflow by VIC hydrological model as well as XAJ hydrological model driven by observed precipitation and TMPA products of the Ganjiang River basin was shown in Figure 8. 
It was noted that the simulated streamflow by the VIC hydrological model driven by 3B42V6 and 3B42V7 agreed well with that of observed precipitation with high CC values (0.88 and 0.89), high NSCE $(0.78$ and 0.79$)$ and low $\mathrm{RB}(0.13 \%$ and $0.99 \%)$, respectively. Therefore, the $3 \mathrm{~B} 42 \mathrm{~V} 7$ products were better than 3B42V6 for the streamflow simulation when using the VIC hydrological model. However, the RB, NSCE and CC values were $28.15 \%, 0.66$ and 0.88 by using the XAJ hydrological model driven by the 3B42V7 product in the Ganjiang River basin, respectively. It was clearly that the VIC hydrological model demonstrated better performance than the XAJ hydrological model with a higher NSCE value except for the 3B42RTV6 product.
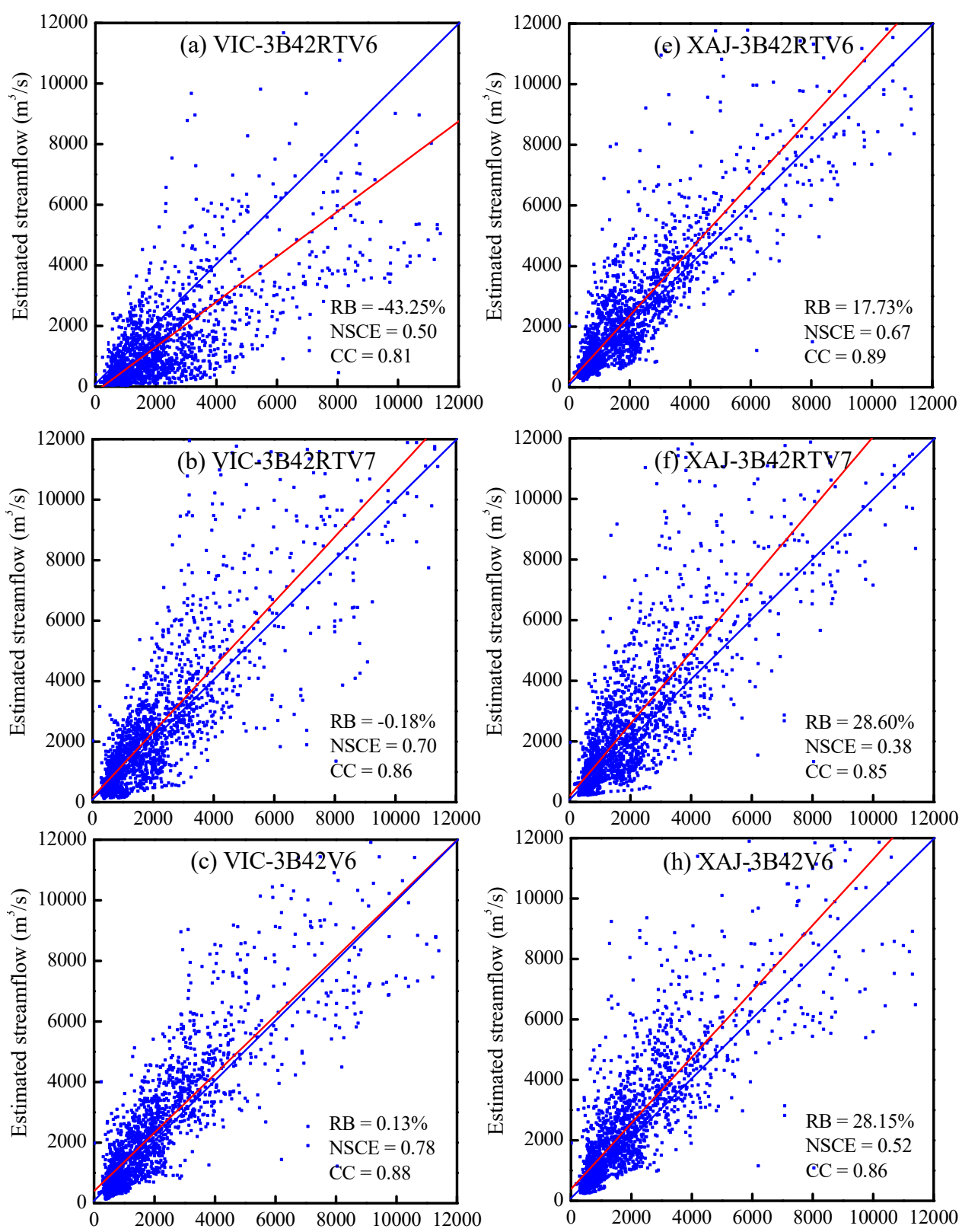

Figure 8. Cont. 

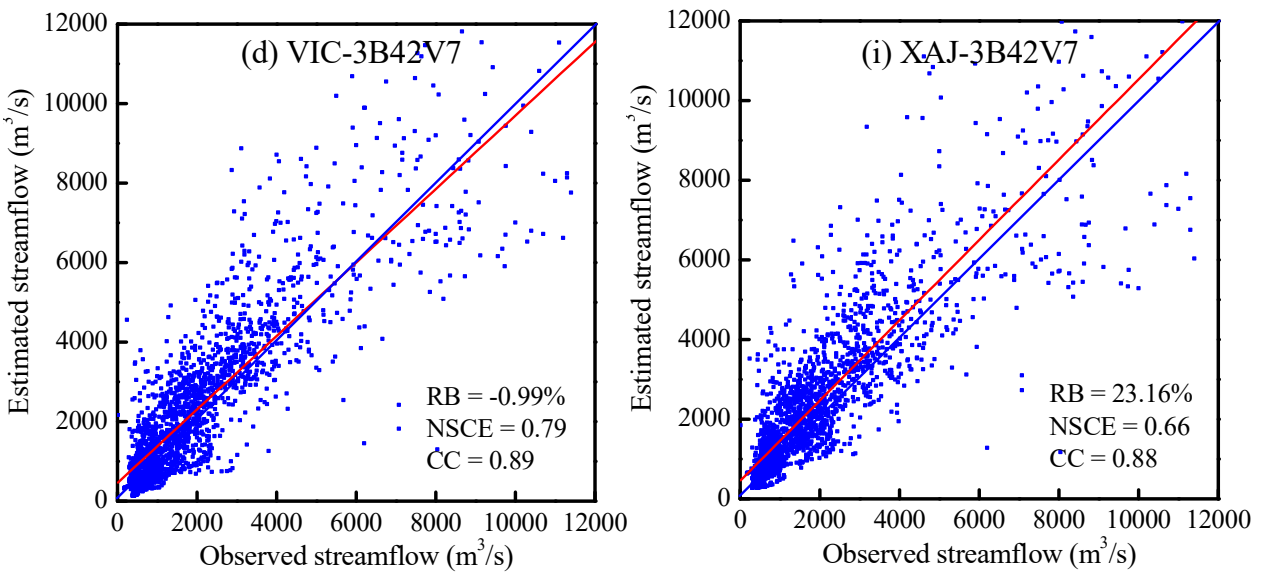

Figure 8. Scatter plots of the observed and simulated streamflow by using VIC and XAJ hydrological models in the Ganjiang River basin ((a-d) VIC; (f-i) XAJ).

The VIC hydrological model was used to evaluate the 3B42V7 and GPM products hydrologic utility in the Ganjiang River basin during the period March 2014 to June 2015. As was shown in Figure 9, the patterns of the simulated streamflow based on the 3B42V7 and GPM precipitation data by using VIC hydrological model in the Ganjiang River basin were similar to that of the observed streamflow. However, the simulated streamflow consistently underestimated the peaks between 12 June 2014 and 12 December 2014, especially in the period from 12 June 2014 and 12 September 2014. Overall, a good agreement existed between the observed and simulated series in the daily time scales.

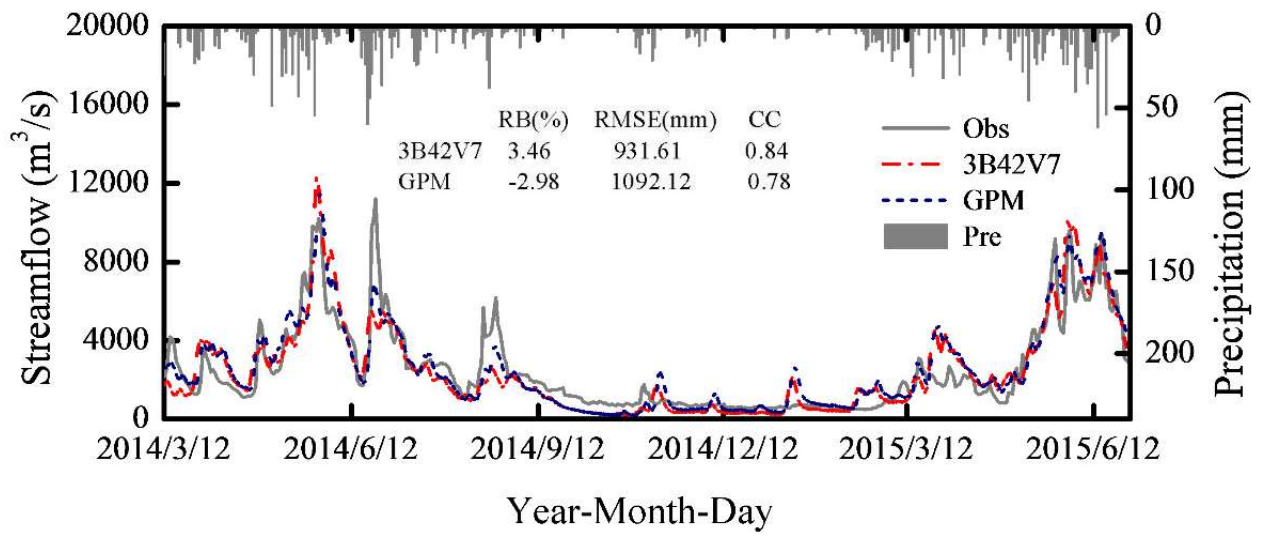

Figure 9. Comparison of the observed and simulated streamflow based on the 3B42V7 and GPM precipitation data by using VIC hydrological model in the Ganjiang River basin.

Cumulative probabilities of precipitation and streamflow in the Ganjiang River basin were shown in Figure 10. The results showed that the cumulative probabilities of precipitation in the Ganjiang River basin for the 3B42RTV7, 3B42V6, and 3B42V7 products were higher than that of observed precipitation, while the cumulative probability of precipitation for the 3B42RTV6 was lower than that of the observed precipitation. It indicated that the cumulative probabilities of streamflow simulation driven by TMPA products were higher than that of the observed precipitation in the Ganjiang River basin by using the XAJ hydrological model. Generally, the cumulative probabilities of streamflow by the VIC hydrological model driven by the observed precipitation, 3B42RTV7, 3B42V6 and 3B42V7 were similar to that of the observed streamflow in the Ganjiang River basin. Meanwhile, the cumulative probability of precipitation by the VIC hydrological model driven by 3B42RTV6 was much lower than that of observation. Moreover, the differences between the observed and simulated probability distributions were significant by using the Kolmogorov-Smirnov statistic method $(p<0.05)$. 

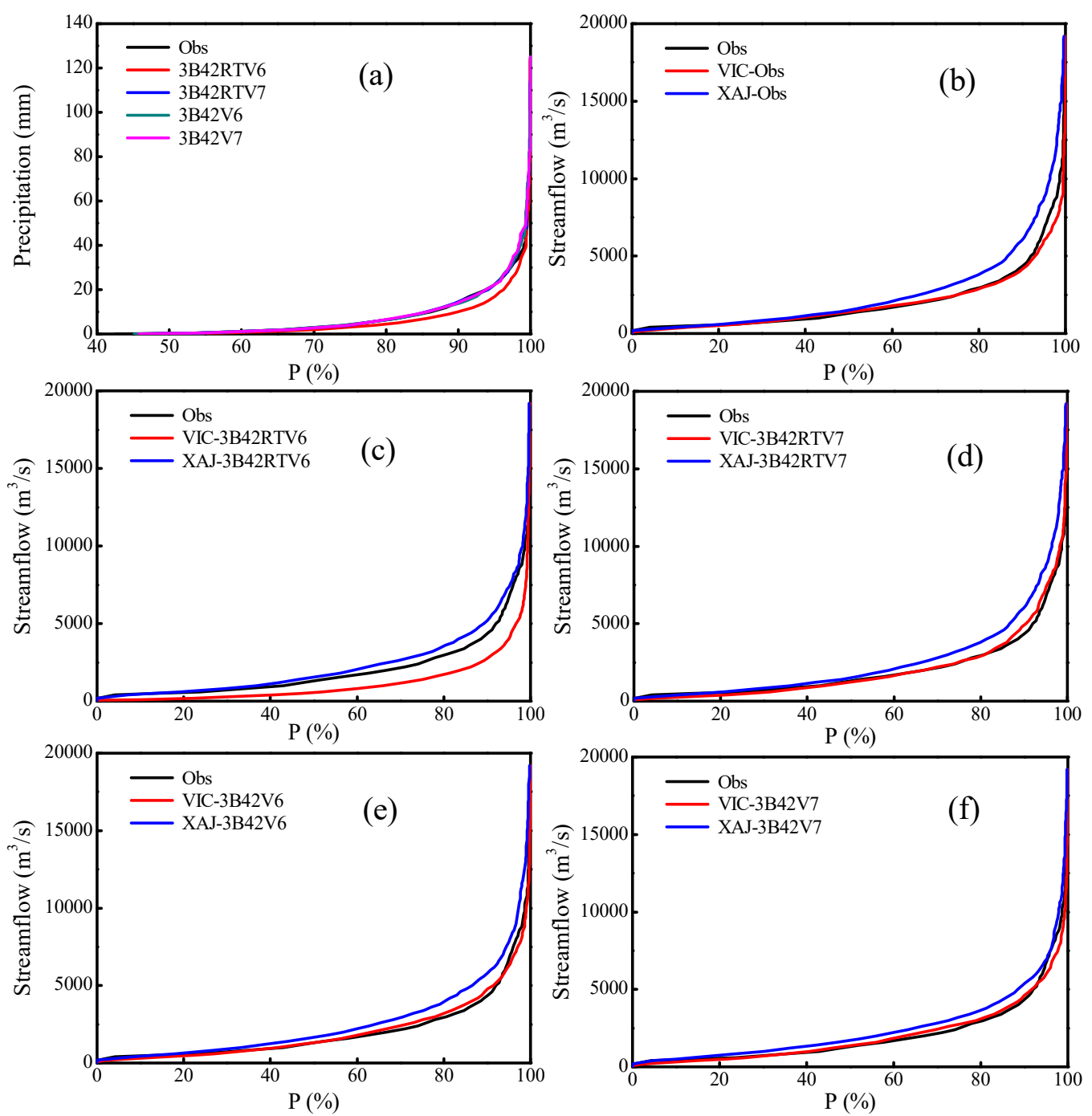

Figure 10. Cumulative probabilities of the observed streamflow and simulated streamflow using the XAJ and VIC hydrological models in the Ganjiang River basin (the difference in the observed and simulated probability distributions was statistically significant at the 0.05 significance level with Kolmogorov-Smirnov statistic).

The statistical indices (POD, CSI, and FAR) for different streamflow thresholds of the VIC and XAJ models were shown in Figure 11. High values of POD and CSI at streamflow from 2000-6000 $\mathrm{m}^{3} / \mathrm{s}$ indicated that VIC model driven by TRMM precipitation products performed better (Figure 11a,b). However, there was a poor performance for the 3B42RTV6 precipitation in the streamflow simulation by using the VIC model. The POD and CSI values decreased obviously while the FAR increased as the streamflow getting bigger and bigger, which indicated the limited capability of VIC model driven by 3B42RTV7, 3B42V6 and 3B42v7 for detecting large streamflow (Figure 11a-c). The relatively higher POD and CSI also revealed that all the TRMM products showed good performance in simulating streamflow in the humid basin of China except 3B42RTV6 by using the VIC model, especially for streamflow rates of $2000-6000 \mathrm{~m}^{3} / \mathrm{s}$. As was shown in Figure 11, there was a good performance in simulating streamflow in the Ganjiang River basin, especially for the streamflow from $2000-7000 \mathrm{~m}^{3} / \mathrm{s}$. It also can be found that both the GPM and 3B42V7 precipitation products performed well in simulating extreme streamflow in this basin by using VIC hydrologic model, especially for the streamflow simulation from $2000-5000 \mathrm{~m}^{3} / \mathrm{s}$. However, the product of 3B42V7 performed much better than the GPM product in detecting extreme streamflow events, especially for the streamflow of $2000-7000 \mathrm{~m}^{3} / \mathrm{s}$ (Figure 11g-i). 

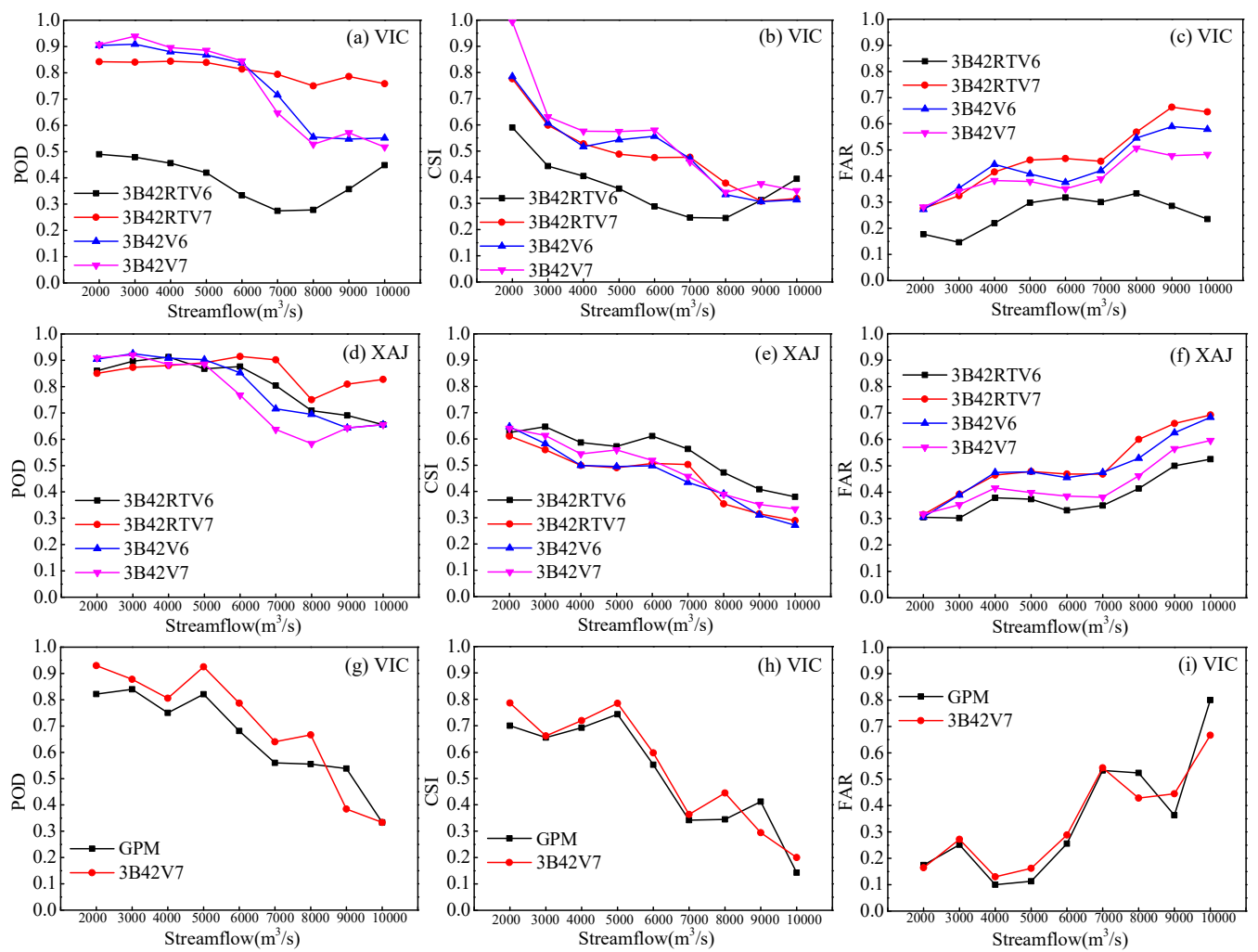

Figure 11. Daily statistical indices for different streamflow thresholds of VIC and XAJ model $((\mathbf{a}, \mathbf{d}, \mathbf{g})$ POD; (b,e,h) CSI and (c,f,ii) FAR).

\section{Discussion}

Satellite precipitation products have played an important role in hydro-relation applications by hydrologic modelers, climate searchers and scientists in other scientific communities $[5,8,18]$. The upgrade of TMPA from 3B42V6 to 3B42V7 provides the users with higher-quality QPE products that were better in applications. In this paper, we found that the upgraded 3B42V7 TMPA precipitation products, including research product and the real-time product, showed distinct improvement over previous 3B42V6 counterparts in a humid basin (Ganjiang River basin). This conclusion was the same as many other researches [37]. For example, Huang et al. [38] revealed that 3B42V7 and 3B42RTV7 have higher precipitation estimation accuracy than 3B42V6 and 3B42RTV6. Fei et al. [12] revealed that 3B42V6 and 3B42V7 agreed well with the actual annual rainfall at the year scale in humid southern China, while the two products had poor performance at the day and month scale. Zhu et al. [39] demonstrated that the two 3B42 products agreed better with gauge precipitation data than the two products of 3B42RT. Fei et al. [12] and Huang et al. [38] indicated that the 3B42V7 product has the highest precipitation estimation accuracy, which could understand the complex hydrological process better, while the product of 3B42RTV7 showed a greater improvement than 3B42RTV6.

The success of 3B42V7 TMPA casts a confidence vote for the TMPA developers in developing higher resolution QPE products with observations from the GPM that was launched in February of 2014. In this paper, the GPM precipitation products showed better agreement with gauge observation than the 3B42V7, which agreed fairly with gauge observations with lower RB (1.34\%) and higher CC (0.99) at monthly scale. However, there were no significant advantages for the GPM precipitation product than that of the 3B42V7, which was different to previous studies [37,40]. The reason may be that the GPM IMERG data were resampled to the same spatial resolution by using the Kriging interpolation method $\left(0.25^{\circ}\right)$ to make them comparable. The potential errors would possibly be introduced during the resampling procedure. Other researchers have made similar findings, for example, Chen Cheng et al. [15] investigated the impact of the initial $\left(0.25^{\circ}\right)$ and the interpolated $\left(0.1^{\circ}\right)$ 
TRMM data had different performances at multiple scales, and they thought there might be a typical scale mismatch issue between point-based rain gauge data and the gridded precipitation products, therefore the comparison of different interpolation methods is necessary to obtain higher precision for precipitation. Omranian [16] also studied the impact of temporal and spatial downscaling of different satellite products (near/post-real-time) on their accuracy and they found that the GPM satellite rainfall products showed better performance when the temporal and spatial resolutions were downscaled.

The accuracy of precipitation is important for the improvement of hydrological simulation [1,2]. The hydrologic performance of TMPA and GPM IMERG satellite-based precipitation were evaluated by using the VIC and XAJ hydrological models in the Ganjiang River basin of China. This paper compared the streamflow simulated by the XAJ and VIC hydrological models using satellite products. It can be found that the simulated streamflow driven by the products of 3B42RTV7 (V7) performed better than the 3B42RTV6 (V6). And the VIC hydrological model outperformed the XAJ hydrological model with lower RB, higher NSCE, and higher CC values. Although the VIC and XAJ hydrological models can be used in the streamflow simulation in the Ganjiang River basin, the streamflow simulated by the VIC hydrological model driven by the 3B42V7 underestimated by $0.99 \%$, and it overestimated the streamflow by $23.16 \%$ driven by XAJ hydrological model. As a whole, the 3B42V7 TMPA precipitation products, especially the real-time product 3B42RTV7, showed better potentials than that of 3B42RTV6 (V6) in hydrology utility. Some researches obtained the same conclusion [11,38]. Huang et al. [38] and Chen et al. [25] found that the product of 3B42RTV7 performed better than the 3B42RTV6 product in the hydrological simulation as well. The 3B42RTV7 and 3B42V7 products could simulate the streamflow well by utilizing the VIC and XAJ hydrological model, respectively [11]. Different spatial and temporal resolutions can also change the accuracy of the satellite products and subsequently alter the accuracy of the hydrological simulation. Therefore, the TRMM-era satellite rainfall products still have limitations in terms of resolution and accuracy in the complex areas, especially for the mountainous [21,41,42].

Estimating precipitation accurately is very important due to their susceptibility to hazards [43]. Hence, caution should be kept in the minds of TMPA users for hydrological modeling and natural hazards modeling and monitoring when TMPA products are used as inputs. Mei and Anagnostou [43] indicated the products of 3B42V6 and 3B42V7 performed better in quantifying and detecting hazards. Jiang et al. [11] revealed that the 3B42RTV7 and 3B42V7 products showed nice performance in estimating extreme precipitation in the Ganjiang River basin. Omranian et al. [18] found that the GPM product could reconstruct precipitation and recognize the spatial variability of the storm well. Prakash et al. [44] also indicated that the product of GPM performed much better than the TRMM products in detecting heavy rainfall in India. As for the hydrologic utilization, Jiang et al. [11] used the VIC hydrological model to simulate the streamflow in the Ganjiang River basin, and discovered that 3B42RTV7/3B42V7 precipitation products perform nicely in the extreme streamflow estimation in this basin. Tang et al. [14] and Wang et al. [45] revealed that the GPM showed better hydrological performance than the product of 3B42V7 at the mid-latitude and high-latitude, along with relatively dry climate regions. However, Chen et al. [13] found that the 3B42RTV7 product presented a slight downgraded performance than the product of 3B42RTV6 at the daily scale. Both of the TMPA and GPM precipitation products have their own strengths and weakness and different models perform differently in the streamflow simulation [46]. It was expected that the 3B42RTV7 (V7) and GPM IMERG will further improve the QPE products for hydro-meteorological applications such as floods and landslide.

\section{Conclusions}

This study evaluated four widely used global high-resolution satellite precipitation products against gauge observations and higher resolution QPE products with observations from GPM over the Ganjiang River basin. Numerous satellite precipitation validation studies have been implemented with an aim to give both products' users and algorithm developers the information about the quality of satellite precipitation estimates. The main findings of this study can be summarized as follows: 
(1) The 3B42RTV7 $(\mathrm{RB}=2.97 \%$, RMSE $=5.69 \mathrm{~mm}$, and $\mathrm{CC}=0.79)$ had better performance than that of 3B42RTV6 $(\mathrm{RB}=-24.15 \%$, RMSE $=5.98 \mathrm{~mm}$, and $\mathrm{CC}=0.72)$. And the 3B42V7 $(\mathrm{RB}=2.95 \%, \mathrm{RMSE}=5.24 \mathrm{~mm}$, and $\mathrm{CC}=0.82)$ perform better than that of $3 \mathrm{~B} 42 \mathrm{~V} 6(\mathrm{RB}=3.60 \%$, RMSE $=5.56 \mathrm{~mm}$, and CC $=0.80$ ) with higher CC and lower RMSE value at daily time scale. For the monthly statistics of satellite rainfall products, the 3B42V6 was observed to achieve all the best indexes of RB $(0.01 \%)$ and CC (0.95) except RMSE $(1.04 \mathrm{~mm})$, and the 3B42V7 was found to attain all the best indexes of RMSE $(1.00 \mathrm{~mm})$ and CC (0.95) except RB (1.06\%). Overall, the 3B42V6 and 3B42V7 perform better than the 3B42RTV6 and 3B42RTV7.

(2) The 3B42RTV6 and 3B42V7 have good hydrological performance in the streamflow simulation by the VIC and XAJ hydrological models with higher NSCE and CC values. The 3B42RTV6 and 3B42RTV7 demonstrated lower NSCE score (0.50 vs. 0.70). In general, 3B42RTV6 and 3B42RTV7 showed higher CC $(>0.8)$ in simulating stream flow by the VIC and XAJ hydrological model.

(3) The streamflow simulated by the VIC hydrological model driven by the 3B42V7 underestimated by $0.99 \%$, however, it overestimated the stream flow by $23.16 \%$ simulated by the XAJ hydrological model. The 3B42V7 generally outperformed 3B42V6 in terms of hydrologic performance, and the VIC hydrological model generally outperformed the XAJ hydrological model with lower $\mathrm{RB}$, higher NSCE, and higher CC values. Of course, the conceptual hydrological model was enough for the hydrologic evaluation of TRMM and GPM IMERG satellite-based precipitation in a humid basin of China. This study provides a reference for the comparison of multiple models on watershed scale.

Author Contributions: Z.Z. provided the datasets including the required supporting software needed for the analyses; Z.Z., S.C. and Z.D. cooperated in designing and improving the concept of the research project and related processes; J.T. and Y.H. conducted the data processing and analysis. All the authors participated actively in preparing and reviewing the manuscript.

Acknowledgments: This paper is financially supported by National Natural Science Foundation of China (Grant No. 91747203 and 41171020) and Distinguished Young Scholars Fund of Nanjing Forestry University (NLJQ2015-01) and the project supported by the Six Talent Peaks project in Jiangsu Province (Grant no. 2015-JY-017). We would like to thank the National Climate Centre in Beijing for providing valuable climate datasets.

Conflicts of Interest: The authors declare no conflict of interest.

\section{References}

1. Gourley, J.J.; Vieux, B.E. A Method for Evaluating the Accuracy of Quantitative Precipitation Estimates from a Hydrologic Modeling Perspective. J. Hydrol. 2005, 6, 115-133. [CrossRef]

2. Gourley, J.J; Vieux, B.E. A method for identifying sources of model uncertainty in rainfall-runoff simulations. J. Hydrol. 2006, 327, 68-80. [CrossRef]

3. Huffman, G.J.; Adler, R.F.; Morrissey, M.M.; Bolvin, D.T.; Curtis, S.; Joyce, R.; Mcgavock, B.; Susskind, J. Global Precipitation at One-Degree Daily Resolution from Multisatellite Observations. J. Hydrol. 2001, 2, 36-50. [CrossRef]

4. McLaughlin, D. An integrated approach to hydrologic data assimilation: Interpolation, smoothing, and filtering. Adv. Water. Resour 2002, 25, 1275-1286. [CrossRef]

5. Jiang, S.; Ren, L.; Hong, Y.; Yong, B.; Yang, X.; Yuan, F.; Ma, M. Comprehensive evaluation of multi-satellite precipitation products with a dense rain gauge network and optimally merging their simulated hydrological flows using the Bayesian model averaging method. J. Hydrol. 2012, 452, 213-225. [CrossRef]

6. Chen, S.; Hong, Y.; Cao, Q.; Gourley, J.J.; Kirstetter, P.; Yong, B.; Tian, Y.; Zhang, Z.; Shen, Y.; Hu, J.; et al. Similarity and difference of the two successive V6 and V7 TRMM multisatellite precipitation analysis performance over China. JGR Atmos. 2013, 118, 13060-13074. [CrossRef]

7. Huffman, G.J.; Bolvin, D.T.; Nelkin, E.J.; Wolff, D.B.; Adler, R.F.; Gu, G.; Hong, Y.; Bowman, K.P.; Stocker, E.F. The TRMM Multisatellite Precipitation Analysis (TMPA): Quasi-Global, Multiyear, Combined-Sensor Precipitation Estimates at Fine Scales. J. Hydrol. 2007, 8, 38-55. [CrossRef]

8. Liu, Z. Comparison of versions 6 and 73-hourly TRMM multi-satellite precipitation analysis (TMPA) research products. Atmos. Res. 2015, 163, 91-101. [CrossRef] 
9. Prakash, S.; Mitra, A.K.; Momin, I.M.; Pai, D.S.; Rajagopal, E.N.; Basu, S. Comparison of TMPA-3B42 Versions 6 and 7 Precipitation Products with Gauge-Based Data over India for the Southwest Monsoon Period. J. Hydrol. 2015, 16, 346-362. [CrossRef]

10. Yong, B.; Chen, B.; Gourley, J.J.; Ren, L.; Hong, Y.; Chen, X.; Wang, W.; Chen, S.; Gong, L. Intercomparison of the Version-6 and Version-7 TMPA precipitation products over high and low latitudes basins with independent gauge networks: Is the newer version better in both real-time and post-real-time analysis for water resources and hydrologic extremes? J. Hydrol. 2014, 508, 77-87.

11. Jiang, S.; Zhang, Z.; Huang, Y.; Chen, X.; Chen, S. Evaluating the TRMM Multisatellite Precipitation Analysis for Extreme Precipitation and Streamflow in Ganjiang River Basin, China. Adv. Meteorol. 2017, 2017, 2902493. [CrossRef]

12. Fei, M.; Zhang, Z.; Yuan, L. Accuracy Assessmant for TRMM in the Poyang Lake Basin. Resour. Environ. Yangtze Basin 2015, 24, 1323-1330, (In Chines with English abstract).

13. Islam, T.; Rico-Ramirez, M.A.; Han, D.; Srivastava, P.K.; Ishak, A.M. Performance evaluation of the TRMM precipitation estimation using ground-based radars from the GPM validation network. J. Atmos. Sol.-Terr. Phys. 2012, 77, 194-208. [CrossRef]

14. Tang, G.; Ma, Y.; Long, D.; Zhong, L.; Hong, Y. Evaluation of GPM Day-1 IMERG and TMPA Version-7 legacy products over Mainland China at multiple spatiotemporal scales. J. Hydrol. 2016, 533, 152-167. [CrossRef]

15. Chen, C.; Chen, Q.; Duan, Z.; Mo, K.; Li, Z.; Tang, G. Multiscale comparative evaluation of the GPM IMERG v5 and TRMM 3B42 v7 precipitation products from 2015 to 2017 over a climate transition area of China. Remote Sens. 2018, 10, 944. [CrossRef]

16. Omranian, E.; Sharif, H.O. Evaluation of the Global Percipitation Measurement (GPM) Satellite Rainfall Products over the Lower Colorad River Basin,TEXAS1. J. Am. Water Resour. 2018, 54, 882-898. [CrossRef]

17. Omranian, E.; Sharif, H.; Tavakoly, A. How Well Can Global Precipitation Measurement (GPM) Capture Hurricanes? Case Study: Hurricane Harvey. Remote Sens. 2018, 10, 1150. [CrossRef]

18. Adler, R.F.; Huffman, G.J.; Chang, A.; Ferraro, R.; Xie, P.; Janowiak, J.; Rudolf, B.; Schneider, U.; Curtis, S.; Bolvin, D.; et al. The Version-2 Global Precipitation Climatology Project (GPCP) Monthly Precipitation Analysis (1979-Present). J. Hydrol. 2003, 4, 1147-1167. [CrossRef]

19. Tobin, K.J.; Bennett, M.E. Using Swat to Model Streamlow in Two River Basins with Ground and Satellite Precipitaion Data1. J. Am. Water Resour. 2009, 45, 253-271. [CrossRef]

20. Xue, X.; Hong, Y.; Limaye, A.S.; Gourley, J.J.; Huffman, G.J.; Khan, S.I.; Dorji, C.; Chen, S. Statistical and hydrological evaluation of TRMM-based Multi-satellite Precipitation Analysis over the Wangchu Basin of Bhutan: Are the latest satellite precipitation products 3B42V7 ready for use in ungauged basins? J. Hydrol. 2013, 499, 91-99. [CrossRef]

21. Behrangi, A.; Khakbaz, B.; Jaw, T.C.; AghaKouchak, A.; Hsu, K.; Sorooshian, S. Hydrologic evaluation of satellite precipitation products over a mid-size basin. J. Hydrol. 2011, 397, 225-237. [CrossRef]

22. Hong, X.; Guo, S.; Xiong, L.; Liu, Z. Spatial and temporal analysis of drought using entropy-based standardized precipitation index: A case study in Poyang Lake basin, China. Appl. Clim. 2015, 122, 543-556. [CrossRef]

23. Zhang, Y.; You, Q.; Chen, C.; Li, X. Flash droughts in a typical humid and subtropical basin: A case study in the Gan River Basin, China. J. Hydrol. 2017, 551, 162-176. [CrossRef]

24. Shankman, D.; Keim, B.D.; Song, J. Flood frequency in China's Poyang Lake region: Trends and teleconnections. Int. J. Clim. 2006, 26, 1255-1266. [CrossRef]

25. Chen, S.; Hu, J.; Zhang, Z.; Behrangi, A.; Hong, Y.; Gebregiorgis, A.S.; Cao, J.; Hu, B.; Xue, X.; Zhang, X. Hydrologic Evaluation of the TRMM Multisatellite Precipitation Analysis Over Ganjiang Basin in Humid Southeastern China. IEEE. J. 2015, 8, 4568-4580. [CrossRef]

26. Tang, G.; Zeng, Z.; Long, D.; Guo, X.; Yong, B.; Zhang, W.; Hong, Y. Statistical and Hydrological Comparisons between TRMM and GPM Level-3 Products over a Midlatitude Basin: Is Day-1 IMERG a Good Successor for TMPA 3B42V7? J. Hydrol. 2016, 17, 121-137. [CrossRef]

27. Guoqiang, T.; Wei, W.; Ziyue, Z.; Xiaoin, G.; Na, L.; Di, L.; Yang, H. An Overview of the Global Precipitation Measurement (GPM) Mission and It's Latest Development. Remote Sens. Technol. Appl. 2015, 30, 607-615. (In Chinese with English abstract)

28. Rozante, J.; Vila, D.; Barboza Chiquetto, J.; Fernandes, A.; Souza Alvim, D. Evaluation of TRMM/GPM Blended Daily Products over Brazil. Remote Sens. 2018, 10, 882. [CrossRef] 
29. Renjun, Z. The Xinanjiang model applied in China. J. Hydrol. 1992, 135, 371-381. [CrossRef]

30. Liang, X. Two-layer variable infiltration capacity land surface representation for general circulation models. Ph.D. Thesis, Washington University, Washington, DC, USA.

31. Wilks, D. International Geophysics; Elsevier: Kidlington, UK, 1995; pp. 2-676.

32. Ebert, E.E.; Janowiak, J.E.; Kidd, C. Comparison of Near-Real-Time Precipitation Estimates from Satellite Observations and Numerical Models. Bull. Am. Meteorol. Soc. 2007, 88, 47-64. [CrossRef]

33. El Kenawy, A.M.; Lopez-Moreno, J.I.; McCabe, M.F.; Vicente-Serrano, S.M. Evaluation of the TMPA-3B42 precipitation product using a high-density rain gauge network over complex terrain in northeastern Iberia. Glob. Planet Chang. 2015, 133, 188-200. [CrossRef]

34. Jiabin, X.; Qinglian, Z.; Qifeng, S.; Xiaoping, L.; Mingli, D. Remote Raman spectral peak searching algorithm based on Kolmogorov-Smirnov test. Chin. J. Sci. Instrum. 2018, 39, 141-147, (In Chines with English abstract).

35. Makarov, A.A.; Simonova, G.I. Some Properties of Two-Sample Kolmogorov-Smirnov Test in the Case of Contamination of One of the Samples. J. Math. Sci. 2017, 220, 718-723. [CrossRef]

36. Yapo, P.O.; Gupta, H.V.; Sorooshian, S. Multi-objective global optimization for hydrologic models. J. Hydrol. 1998, 204, 83-97. [CrossRef]

37. Chen, S.; Hong, Y.; Gourley, J.J.; Huffman, G.J.; Tian, Y.; Cao, Q.; Yong, B.; Kirstetter, P.; Hu, J.; Hardy, J.; et al. Evaluation of the successive V6 and V7 TRMM multisatellite precipitation analysis over the Continental United States. Water Resour. Res. 2013, 49, 8174-8186. [CrossRef]

38. Huang, Y.; Zhang, Z.; Fei, M.; Jin, Q. Hydrological Evaluation of the TMPA Multi-satellite Precipitation Esitimates over the Ganjiang Basin. Resour. Environ. Yangtze Basin 2016, 25, 1618-1625, (In Chines with English abstract).

39. Zhu, H.; Li, Y.; Huang, Y.; Li, Y.; Hou, C.; Shi, X. Evaluation and hydrological application of satellite-based precipitation datasets in driving hydrological models over the Huifa river basin in Northeast China. Atmos. Res. 2018, 207, 28-41. [CrossRef]

40. Nair, S.; Srinivasan, G.; Nemani, R. Evaluation of Multi-Satellite TRMM Derived Rainfall Estimates over a Western State of India. J. Meteorol. Soc. Jpn. 2009, 87, 927-939. [CrossRef]

41. Yong, B.; Ren, L.; Hong, Y.; Wang, J.; Gourley, J.J.; Jiang, S.; Chen, X.; Wang, W. Hydrologic evaluation of Multisatellite Precipitation Analysis standard precipitation products in basins beyond its inclined latitude band: A case study in Laohahe basin, China. Water Resour. Res. 2010, 46, W07519. [CrossRef]

42. Tian, Y.; Peters-Lidard, C.D.; Adler, R.F.; Kubota, T.; Ushio, T. Evaluation of GSMaP Precipitation Estimates over the Contiguous United States. J. Hydrol. 2010, 11, 566-574. [CrossRef]

43. Mei, Y.; Anagnostou, E.N.; Nikolopoulos, E.I.; Borga, M. Error Analysis of Satellite Precipitation Products in Mountainous Basins. J. Hydrol. 2014, 15, 1778-1793. [CrossRef]

44. Prakash, S.; Mitra, A.K.; Pai, D.S.; AghaKouchak, A. From TRMM to GPM: How well can heavy rainfall be detected from space? Adv. Water Resour. 2016, 88, 1-7. [CrossRef]

45. Wang, Z.; Zhong, R.; Lai, C.; Chen, J. Evaluation of the GPM IMERG satellite-based precipitation products and the hydrological utility. Atmos. Res. 2017, 196, 151-163. [CrossRef]

46. Zhang, Y.; Sun, A.; Sun, H.; Gui, D.; Xue, J.; Liao, W.; Yan, D.; Zhao, N.; Zeng, X. Error adjustment of TMPA satellite precipitation estimates and assessment of their hydrological utility in the middle and upper Yangtze River Basin, China. Atmos. Res. 2019, 216, 52-64. [CrossRef]

(C) 2019 by the authors. Licensee MDPI, Basel, Switzerland. This article is an open access article distributed under the terms and conditions of the Creative Commons Attribution (CC BY) license (http:// creativecommons.org/licenses/by/4.0/). 